\title{
Activity of spiramycin against Toxoplasma gondii in vitro, in experimental infections and in human infection
}

\author{
Hernan R. Chang and Jean-Claude F. Pechère \\ Department of Microbiology, University of Geneva Medical School, \\ C.M.U., 9 avenue de Champel, 1211 Geneva 4, Switzerland
}

\begin{abstract}
The in-vitro, experimental and clinical activities of spiramycin against Toxoplasma gondii have been reviewed. In mammalian cells infected by $T$. gondii as in various experimental models, spiramycin definitively exerts an inhibitory antitoxoplasmic effect which, clinically, seems useful for preventing congenital toxoplasma infection during pregnancy or for reducing the inflammation in toxoplasmic chorioretinitis. However, spiramycin does not kill the parasite efficiently, and cannot be recommended for eradicating the most severe forms of toxoplasmosis.
\end{abstract}

\section{Introduction}

Infections due to the intracellular protozoan parasite Toxoplasma gondii are frequent among animals and man all over the world. Fortunately, only a small percentage of those infections produce toxoplasmosis. Exceptions are acute infections in pregnant women, chorioretinitis and recrudescences in immunocompromised hosts which cause major concerns because they can lead to dramatic sequelae or life-threatening toxoplasmosis. The infected fetus often develops serious sequelae such as impaired vision or neurological disorders, even after five years post-partum (Koppe, LoewerSieger \& De Roever-Bonnet, 1986). AIDS patients have a striking propensity for the development of a life-threatening infection such as toxoplasmic encephalitis.

Current therapy with the combination of pyrimethamine and sulphadiazine (or triple sulphonamides) (Eyles \& Coleman, 1955) has the disadvantage of producing many adverse and even toxic effects (Kutscher, Lane \& Segael, 1954; Kaufman \& Geisler, 1960). In some cases, especially in AIDS patients, these effects force discontinuation of therapy, leading to an almost inevitable relapse which frequently will not respond to the same therapy again (Haverkos, 1987; Wanke et al., 1987). Thus, there is an urgent need for alternative safer therapy for this disease.

Spiramycin is a macrolide antibiotic derived from Streptomyces ambofaciens with an antibacterial activity comparable to that of erythromycin (Ravina et al., 1956). Early studies showed that spiramycin had some activity against toxoplasmosis in mice and rabbits (Bogacz, 1956; Garin \& Eyles, 1958; Mas Bakal \& In't Veld, 1965). Since then, spiramycin has been used in many countries for the treatment of human toxoplasmosis without showing any evidence of harmful effects on fetal development or toxicity. We review here the results of in-vitro, experimental and clinical investigations which have been performed with this compound. 


\section{Animal models of toxoplasmosis}

\section{Murine models}

In mice, the RH, BK and Beverley strains of $T$. gondii have been used. These strains differ in their virulence to mice, the $\mathrm{RH}$ being known as especially virulent (Sabin, 1941). However, murine susceptibility depends not only on the parasitic strain, but also on the strain of mouse.

Acute toxoplasmosis. In mice, a lethal acute toxoplasmosis is produced by inoculation of tachyzoites of a virulent strain. After intraperitoneal challenge, the experimental disease is characterized by the development of a disseminated infection and the production of ascites containing numerous tachyzoites. The activity of a drug is assessed by its ability to permit the survival of treated infected mice after a given observation time. When no parasites are seen at autopsy in the surviving animals, their organs are ground in a mortar and portions of these suspensions are injected into new mice. The donors are considered cured when the recipient mice survive a defined number of days after the subinoculation and show no toxoplasma at autopsy.

Table I summarizes results obtained after various treatments of spiramycin. In the preliminary studies of Bogacz (1956) the parasite inocula were not standardized before the inoculation of the mice, so that it is not possible to correlate the number of parasites inoculated with the respective antibiotic dose affording protection. Later spiramycin therapy protecting all infected mice was obtained in animals challenged with low inocula (500 tachyzoites or less) and treated with at least $8 \mathrm{mg}$ of spiramycin per day for 14 or 28 days (Bonaduce, 1960; Mas Bakal \& Int' Veld, 1965; Garin \& Paillard, 1984). However, when more stringent experimental conditions were used, the authors were not able to protect $100 \%$ of the infected animals with spiramycin.

Dealing with pregnant mice, Nguyen \& Stadtsbaeder (1975), showed some beneficial therapeutic effect of spiramycin with regard to successful delivery, offspring survival and antitoxoplasma antibody assays in the offspring, but the combination of trimethoprim-sulphamethoxazole performed better in the same model. In addition Beverley et al. (1973) showed that spiramycin (2-10 mg daily for five days each week over four weeks) was effective in preventing the development of pathological changes during the early weeks of life in murine litters with experimental congenital toxoplasma infections.

Chronic toxoplasmosis. Some investigations have been carried out with the Beverley strain of $T$. gondii, which is less virulent to mice showing a large number of cysts in the brains in chronic stage. Compared to control animals, high doses of spiramycin (13 $\mathrm{mg}$ daily for 21 days) considerably prolonged the survival period of mice, but showed only slight killing effects on toxoplasma (Nakayama \& Matsubayashi, 1963).

\section{Experimental induced toxoplasmic uveitis in rabbits}

A series of experiments using spiramycin for treating induced toxoplasma anterior uveitis in rabbits showed that this antibiotic was effective and nontoxic with regard to the treatment of inflammation (Giles, Jacobs \& Melton, 1964).

Acute toxoplasmosis in squirrel monkeys

A fatal systemic disease was produced in squirrel monkeys by oral inoculation of a brain suspension made from mice infected with the Beverley strain of $T$. gondii (Harper, 
Table I. Studies on the activity of spiramycin against acute toxoplasmosis in mice

\begin{tabular}{|c|c|c|c|c|c|c|c|c|}
\hline \multicolumn{3}{|c|}{ T. gondii challenge } & \multicolumn{3}{|c|}{ Therapy } & \multicolumn{2}{|c|}{ Results $(\%)$} & \multirow[t]{2}{*}{ Reference } \\
\hline strain & $\underset{\left(\times 10^{2}\right)}{\text { inoculum }}$ & route & $\begin{array}{c}\text { dose } \\
\text { (mg/day) }\end{array}$ & route & $\begin{array}{l}\text { duration } \\
\text { (days) }\end{array}$ & $\begin{array}{l}\text { survival } \\
\text { rate }\end{array}$ & $\begin{array}{l}\text { cure } \\
\text { rate }\end{array}$ & \\
\hline $\mathrm{U}$ & $\begin{array}{l}\mathrm{U} \\
\mathrm{U} \\
\mathrm{U}\end{array}$ & $\begin{array}{l}\text { ip } \\
\text { ip } \\
\text { ip }\end{array}$ & $\begin{array}{l}5 \\
7 \cdot 5 \\
10\end{array}$ & $\begin{array}{l}\mathrm{sc} \\
\mathrm{sc} \\
\mathrm{sc}\end{array}$ & $\begin{array}{l}8 \\
8 \\
8\end{array}$ & $\begin{array}{r}0 \\
100 \\
100\end{array}$ & $\begin{array}{r}0 \\
66 \\
100\end{array}$ & Bogacz (1956) \\
\hline RH & $\begin{array}{r}200 \\
200 \\
200 \\
200 \\
200 \\
50 \\
100\end{array}$ & $\begin{array}{l}\text { ip } \\
\text { ip } \\
\text { ip } \\
\text { ip } \\
\text { sc } \\
\text { ip } \\
\text { ip }\end{array}$ & $\begin{array}{c}2 \\
4 \\
8 \\
16 \\
8+4 \\
4+8 \\
12+8\end{array}$ & $\begin{array}{l}\mathrm{sc} \\
\mathrm{sc} \\
\mathrm{sc} \\
\mathrm{sc} \\
\mathrm{sc} \\
\mathrm{sc} \\
\mathrm{sc}\end{array}$ & $\begin{array}{c}14 \\
14 \\
14 \\
14 \\
17+8 \\
8+13 \\
1+16\end{array}$ & $\begin{array}{l}30 \\
80 \\
80 \\
20 \\
87 \\
25 \\
62\end{array}$ & $\begin{array}{r}0 \\
40 \\
80 \\
20 \\
100 \\
100 \\
20\end{array}$ & $\begin{array}{l}\text { Garin \& } \\
\text { Eyles (1958) }\end{array}$ \\
\hline $\mathrm{BK}$ & $\begin{array}{r}200 \\
20 \\
2\end{array}$ & $\begin{array}{l}\text { ip } \\
\text { ip } \\
\text { ip }\end{array}$ & $\begin{array}{l}10 \\
10 \\
10\end{array}$ & $\begin{array}{l}\mathrm{sc} \\
\mathrm{sc} \\
\mathrm{sc}\end{array}$ & $\begin{array}{l}7 \\
7 \\
7\end{array}$ & $\begin{array}{r}0 \\
40 \\
100\end{array}$ & $\begin{array}{l}0 \\
\text { ND } \\
100\end{array}$ & Bonaduce (1960) \\
\hline RH & $\begin{array}{l}100-250 \\
100-250\end{array}$ & $\begin{array}{l}\text { ip } \\
\text { ip }\end{array}$ & $\begin{array}{r}8 \\
13\end{array}$ & $\begin{array}{l}\text { po } \\
\text { po }\end{array}$ & $\begin{array}{l}21 \\
21\end{array}$ & $\begin{array}{l}26 \\
48\end{array}$ & $\begin{array}{l}18 \\
26\end{array}$ & $\begin{array}{l}\text { Nakayama \& } \\
\text { Matsubayashi } \\
\text { (1963) }\end{array}$ \\
\hline RH & $\begin{array}{l}1 \\
1\end{array}$ & ip & $\begin{array}{l}8 \\
8\end{array}$ & $\begin{array}{l}\mathrm{sc} \\
\mathrm{sc}\end{array}$ & $\begin{array}{l}14^{a} \\
28^{a}\end{array}$ & $\begin{array}{r}80 \\
100\end{array}$ & $\begin{array}{r}12 \\
100\end{array}$ & $\begin{array}{l}\text { Mas Bakal \& } \\
\text { In't Veld (1965) }\end{array}$ \\
\hline $\mathrm{RH}$ & 5 & ip & 16 & $\mathrm{sc}$ & 14 & 100 & 50 & $\begin{array}{l}\text { Garin \& } \\
\text { Paillard (1984) }\end{array}$ \\
\hline $\mathrm{RH}$ & 50 & ip & $7 \cdot 5$ & po & $5^{a}$ & 50 & 59 & $\begin{array}{l}\text { Chang \& } \\
\text { Pechère } \\
(1987)\end{array}$ \\
\hline
\end{tabular}

All these experiments have been conducted with different strains of white mice weighing $20-30 \mathrm{~g}$. Treatment was started $2-3 \mathrm{~h}$ after challenge except otherwise specified.

ip, Intraperitoneal; sc, subcutaneous; po, per oral.

a $24 \mathrm{~h}$ after challenge.

ND, Not determined.

U, Unknown.

London \& Sever, 1985). Spiramycin was not able to keep the animals from dying. Furthermore, sulphonamides alone or in combinations with pyrimethamine or trimethoprim were significantly more effective than spiramycin in treating toxoplasmosis in this model.

\section{In-vitro models of toxoplasma infection}

T. gondii is an obligate intracellular protozoan which can be cultivated in most mammalian cells. A few experiments have assessed the activity of spiramycin against intracellular T. gondii. Endpoints of these experiments included primarily light microscopy studies determining the number of infected cells, the number of toxoplasma per vacuole and the number of rosette (i.e. eight or more toxoplasma within a single vacuole) containing cells (Nguyen \& Stadtsbaeder, 1975; Kieng Truong et al., 1970; Chang \& Pechère, 1988). Other investigations (Chang \& Pechère, 1988) 
have measured the antitoxoplasmic activity of spiramycin by incorporation of tritiated uracil, a compound which is metabolized by the intracellular parasite but not by the host cell. In addition, the viability of the parasites remaining after antibiotic exposure has been tested by passaging them into a non professional phagocytic cell line (HeLa cells).

All these in-vitro studies yielded the same conclusions. Spiramycin demonstrated antitoxoplasmic activity at relatively high concentrations. For instance, the concentration inhibiting $50 \%\left(\mathrm{IC}_{50}\right)$ of the metabolic activity of intracellular $T$. gondii has been calculated at $218 \mathrm{mg} / 1$. (Chang \& Pechère, 1988). Moreover, the viability test showed that spiramycin had no killing effect when tested at concentrations up to four times the $\mathrm{IC}_{90}$.

\section{Clinical studies}

Spiramycin has been used in many countries for over 27 years. Surprisingly, very few investigations have been directed to assess the actual efficacy of spiramycin in human toxoplasmosis. There are only two published series concerning congential toxoplasmosis (Desmonts \& Couvreur, 1974, 1979). Additional data from the same centre are presented in this volume (Couvreur, Desmonts \& Thulliez, 1988). Acute toxoplasma infection acquired during pregnancy may result in congenital infection. This risk has been evaluated at $15 \%$ in the first trimester, $30 \%$ in the second trimester and $60 \%$ in the third trimester. However, only the toxoplasmic infection acquired during the first trimester of pregnancy has been associated with severe congenital infection. There seems to be a lag period between the maternal and the fetal infection. An antitoxoplasmic treatment is recommended in the hope of preventing the congenital infection provided the diagnosis is made early enough. In this perspective three-week courses of oral spiramycin, alternated with two weeks of no treatment until term, have reduced the incidence of congenital infection from $17 \%$ to $5 \%$ and from $61 \%$ to $23 \%$ (Desmonts \& Couvreur, 1974, 1979).

Patients having active toxoplasmic chorioretinitis must receive specific drug therapy. Chodos \& Habegger-Chodos (1961) showed that in a series of 67 patients spiramycin was an effective agent for use in posterior uveitis presumably caused by toxoplasma. Fajardo, Furguiele \& Leopold (1962) reported a series of 87 patients who had received either spiramycin and steroids, sulphadiazine and pyrimethamine and steroids or steroids therapy alone. They found that although spiramycin therapy resulted in quiescence of posterior uveitis, the combination of sulphadiazine and pyrimethamine was more effective. Cassidy, Bahler \& Minken (1964) and Canamucio, Hallet \& Leopold (1963) reported failures of spiramycin for treating toxoplasmic uveitis. Timsit \& Bloch-Michel, (1987) reported that, in a series of 54 patients diagnosed as having active toxoplasmosis chorioretinitis, the combination of pyrimethamine and sulphadiazine seemed statistically more active than other reported treatments, including therapy with systemic steroids alone or in combination with spiramycin.

\section{Discussion}

The antitoxoplasma activity of spiramycin is supported by converging lines of evidence provided by in-vitro, experimental and clinical studies. Protection of animals from lethal experimental toxoplasmosis within the relatively short time of observation (up to one month), and blockade of the nucleotide synthesis of intracellular parasites shown by uracil incorporation studies indicate essentially an inhibitory effect. Moreover, the 
killing effect of spiramycin against $T$. gondii remains limited as suggested by the invitro viability tests and determination of the cure rate in the mouse experiments. Since $T$. gondii is a eukaryotic cell and spiramycin a macrolide, this activity is somewhat surprising. Early studies have demonstrated that erythromycin inhibits bacterial protein synthesis by binding to the $50 \mathrm{~S}$ ribosomal unit, which prevents elongation of the peptide chain (Pestka, 1977). Spiramycin (and probably all macrolides) act similarly (Menninger \& Otto, 1982). Erythromycin does not bind to mammalian 80S ribosomes, and this accounts in part for its selective toxicity (Mao, Putterman \& Wiegand, 1970). Therefore, in order to explain the activity of spiramycin against $T$. gondii we have to admit one of the two following hypotheses. (i) Spiramycin may interact with the parasite ribosome, as it does with bacteria. However, fractionation of RNA extracted from $T$. gondii by sedimentation revealed the presence of three major RNA components sedimenting at 24S, 19S and 4S to 5S (Remington et al., 1970), a pattern different from that obtained with bacteria. So, in order to prove this hypothesis a macrolide binding site will have to be demonstrated in the ribosomal components of T. gondii. (ii) Spiramycin may have a non ribosomal mode of action. Among the possibilities here, an immuno-modulating effect of spiramycin should be investigated.

Compared with spiramycin, various clinical studies indicate that the combination of pyrimethamine and sulphadiazine is more toxic but more effective for treating severe cases of toxoplasmosis. Thus, spiramycin should be reserved for the treatment of toxoplasmosis when toxicity is particularly unacceptable. This might be the case during pregnancy, for the prevention of congenital toxoplasmosis or in some cases of acute toxoplasmosis in non pregnant patients with normal immune defences, for instance when a prolonged high fever occurs.

\section{References}

Beverley, J. K. A., Freeman, A. P., Henry, L. \& Whelan, J. P. F. (1973). Prevention of pathological changes in experimental congenital toxoplasma infections. Lyon Médical 230, $491-8$.

Bogacz, J. (1956). Action comparée sur les toxoplasmes des diverses substances synthétiques et de quelques antibiotiques dont la spiramycine. Bulletin de la Société de Pathologie Exotique 47, 903-15.

Bonaduce, A. (1960). Ricerche sull'azione della spiramicina nella toxoplasmosi sperimentale del topino bianco. Bollettino della Società Italiana di Biologia Sperimentale 36, 57-9.

Canamucio, C. J., Hallet, J. W. \& Leopold, J. M. (1963). Recurrence of treated toxoplasmic uveitis. American Journal of Ophthalmology 55, 1035-9.

Cassidy, J. V., Bahler, J. W. \& Minken, M. V. (1964). Spiramycin for toxoplasmosis. American Journal of Ophthalmology 57, 227-55.

Chang, H. R. \& Pechère, J.-C. F. (1987). Effect of roxithromycin on acute toxoplasmosis in mice. Antimicrobial Agents and Chemotherapy 31, 1147-9.

Chang, H. R. \& Pechère, J.-C. F. (1988). In vitro effect of four macrolides (roxithromycin, spiramycin, azithromycin [CP-62,993] and A-56268) on Toxoplasma gondii. Antimicrobial Agents and Chemotherapy 32, 524 9.

Chodos, J. B. \& Habegger-Chodos, H. E. (1961). The treatment of ocular toxoplasmosis with spiramycin. Archives of Ophthalmology 65, 401-9.

Couvreur, J., Desmonts, G. \& Thulliez, Ph. (1988). Prophylaxis of congenital toxoplasmosis. Effects of spiramycin on placental infection. Journal of Antimicrobial Chemotherapy 22, Suppl. B, 193-200.

Desmonts, G. \& Couvreur, J. (1974). Congenital toxoplasmosis. A prospective study of 378 pregnancies. New England Journal of Medicine 290, 1110-6.

Desmonts, G. \& Couvreur, J. (1979). Congenital toxoplasmoisis: a prospective study of the offspring of 542 women who acquired toxoplasmosis during pregnancy. In Pathophysiology 
of Congenital Disease (Thalhammer, O., Baumgarten, K. \& Pollack, A., Eds), pp. 51-60. Perinatal Medicine, Sixth European Congress. Georg Thieme Verlag, Stuttgart.

Eyles, D. E. \& Coleman, N. (1955). An evaluation of the curative effects of pyrimethamine and sulfadiazine, alone and in combination, on experimental mouse toxoplasmosis. Antibiotics and Chemotherapy 5, 529-39.

Fajardo, R. V., Furguiele, F. P. \& Leopold, J. M. (1962). Treatment of toxoplasmosis uveitis. Archives of Ophthalmology 67, 712-20.

Garin, J. P. \& Eyles, D. E. (1958). Le traitement de la toxoplasmose expérimentale de la souris par la spiramycine. Presse Médicale 66, 957-8.

Garin, J. P. \& Paillard, B. (1984). Toxoplasmose expérimentale de la souris. Activité comparée de: clindamycine, midécamycine, josamycine, spiramycine, pyriméthamine-sulfadoxine, et triméthoprime-sulfaméthoxazole. Annales de Pédiatrie 31, 841-5.

Giles, C.L., Jacobs, L. \& Melton, M. L. (1964). Chemotherapy of experimental toxoplasmosis. Evaluation of spiramycin alone and in combination. Archives of Ophthalmology 71, 119-27.

Harper, J. S., London, W. T. \& Sever, J. L. (1985). Five drug regimens for treatment of acute toxoplasmosis in squirrel monkeys. American Journal of Tropical Medicine and Hygiene 34, 50-7.

Haverkos, H. (1987). Assessment of therapy for toxoplasma encephalitis. The TE study group. American Journal of Medicine 82, 907-14.

Kaufman, H. E. \& Geisler, P. H. (1960). The hematologic toxicity of pyrimethamine (Daraprim) in man. Archives of Ophthalmology 64, 140-6.

Kieng Truong, T., Garin, J. P., Ambroise-Thomas, P., Despeignes, J. \& Maillard, M. A. (1970). Concentration minimale inhibitrice de spiramycine sur deux souches de toxoplasme (RH Sabin et DC Lyon) entretenues sur système cellulaire BK. Revue de l'Institut Pasteur de Lyon 3, 127-34.

Koppe, J. G., Loewer-Sieger, D. H. \& De Roever-Bonnet, H. (1986). Results of 20-year followup of congenital toxoplasmosis. Lancet $i, 254-5$.

Kutscher, A. H., Lane, S. L. \& Segael, R. (1954). The clinical toxicity of antibiotics and sulfonamides. A comparative review of the literature based on 104,672 cases treated systemically. Journal of Allergy 25, 135-50.

Mas Bakal, P. \& In't Veld, N. (1965). Postponed spiramycin treatment of acute toxoplasmosis in white mice. Tropical and Geographic Medicine 17, 254-60.

Mao, J.-C. H., Putterman, M. \& Wiegand, R. G. (1970). Biochemical basis for selective toxicity of erythromycin. Biochemical Pharmacology 19, 391-9.

Menninger, J. R. \& Otto, D. P. (1982). Erythromycin, carbomycin, and spiramycin inhibit protein synthesis by stimulating the dissociation of peptidyl-tRNA from ribosomes. Antimicrobial Agents and Chemotherapy 21, 811-8.

Nakayama, I. \& Matsubayashi, H. (1963). Effects of spiramycine on experimental toxoplasmosis in mice. Keio Journal of Medicine 12, 117-25.

Nguyen, B. T. \& Stadtsbaeder, S. (1975). In vitro activity of cotrimoxazole on the intracellular multiplication of Toxoplasma gondii. Pathologia Europaea 10, 307-15.

Pestka, S. (1977). Inhibition of protein synthesis. In Molecular Mechanisms of Protein Biosynthesis (Weissbach, H. \& Pestka, S., Eds), pp. 467-553. Academic Press, New York.

Ravina, A., Pestel, M., Eloy, Ph., Duchesnay, G., Albouy, R. \& Rey, M. (1956). A new French antibiotic: spiramycin. In Antibiotics Annual 1955-1956 (Welch, H. \& Marti-Ibáñez, F., Eds), pp. 223-7. Medical Encyclopedia Inc., New York.

Remington, J. S., Bloomfield, M. M., Russell, E. \& Robinson, W. S. (1970). The RNA of Toxoplasma gondii. Proceedings of the Society of Experimental Biology and Medicine 133, 623-6.

Sabin, A. B. (1941). Toxoplasmic encephalitis in children. Journal of the American Medical Association 116, 801-7.

Timsit, J. C. \& Bloch-Michel, E. (1987). Efficacité de la chimiothérapie spécifique dans la prévention des récidives des choriorétinites toxoplasmiques dans les quatre années qui suivent le traitement. Journal Français d'Ophthalmologie 10, 15-23.

Wanke, C., Tuazon, C. U., Kovacs, A., Dina, T., Davis, D. O., Barton, N., et al. (1987). Toxoplasma encephalitis in patients with acquired immune deficiency syndrome: diagnosis and response to therapy. American Journal of Tropical Medicine and Hygiene 36, 509-16. 